\title{
Effects of Size, Time of Day and Sequence of Meal Ingestion on Carbohydrate Tolerance in Normal Subjects
}

\author{
F. J. Service, ${ }^{1,3}$ L. D. Hall, ${ }^{1}$ R. E. Westland, ${ }^{1}$ P.C.O'Brien, ${ }^{5}$ V. L. W. Go, ${ }^{2,3}$ M. W. Haymond ${ }^{1,4}$ and R. A. Rizza ${ }^{1,3}$ \\ ${ }^{1}$ Endocrine Research Unit, ${ }^{2}$ Gastroenterology Research Unit, Departments of ${ }^{3}$ Medicine, ${ }^{4}$ Pediatrics, and \\ ${ }^{5}$ Statistics and Epidemiology, Mayo Medical School and Mayo Clinic, Rochester, Minnesota, USA
}

Summary. The effects of size, time of day and sequence of meal ingestion were determined in healthy subjects using a Latin square design. Plasma glucose, insulin and gastric inhibitory polypeptide, but not glucagon, were correlated with meal size. Plasma glucose, but not insulin, gastric inhibitory polypeptide or glucagon, were greater later in the day. The pro- gressive decline in carbohydrate tolerance from 08.00 to $18.00 \mathrm{~h}$ was associated with impaired insulin secretion estimated by C-peptide, and with impaired insulin action.

Key words: Meal size, sequence, time of day, carbohydrate tolerance, insulin action, insulin secretion.
Man ingests food intermittently and in varying amounts throughout the day. To define the normal post-prandial glucose and hormonal responses under these conditions an examination of the effects of different sizes of meals, time of day of meal ingestion and sequence of ingestion of meals of different sizes on the factors involved in mixed meal tolerance would be required. Plasma glucose responses to varying amounts of orally administered glucose have been reported to correlate with the size of the glucose load in some studies [1-5] but not in others $[6,7]$. No correlation between meals of different sizes and post-prandial plasma glucose responses was observed in the only study to examine this relationship [8]. Although a diurnal variation in tolerance to oral glucose loads has been consistently demonstrated [9-14], it has not been uniformly observed following consumption of mixed meals [15-18]. Furthermore, although glucose tolerance improved following closely timed administration of successive intravenous or oral glucose loads $[19,20]$, it deteriorated if a 3 -h interval was allowed between successive glucose loads [21].

To define the normal post-prandial glucose and hormonal responses to meals which encompass sizes eaten in everyday life, we examined the effects of meal size, time of day, and sequence of meal ingestion on postprandial plasma glucose, insulin, gastric inhibitory polypeptide, and glucagon concentrations and insulin secretion.

\section{Subjects and Methods}

\section{Subjects}

Six lean $(96.5 \pm 3.1 \%$ ideal body weight) healthy subjects (four male, two female; aged $39 \pm 4$ years) volunteered for study after having provided written informed consent.

\section{Methods}

Each subject was studied on three occasions at least two weeks apart in the Clinical Research Center of the Mayo Clinic under a $3 \times 3$ Latin square design. On each study day, meals prepared in the research kitchen were given at $08.00,13.00$ and $18.00 \mathrm{~h}$. Each meal provided $12.5 \%$ (small), $25 \%$ (medium) or $50 \%$ (large) of total daily calories (30 Kcal $/ \mathrm{kg}$ body weight). Meal sizes were selected to reflect those commonly consumed by healthy subjects. The meals varied in size from a snack to a full course meal. On each study day each subject ate one of each of the meal sizes (Table 1). The order of meal ingestion varied from study day to study day, with the order of study days randomized. Three subjects (two male, one female) ingested meals described by sequence 1 ; the sequence of meal ingestion was reversed (sequence 2) for the other three patients (two male, one female).

Each meal was identical both in the proportions of nutrient contents (50\% carbohydrate, $20 \%$ protein, $30 \%$ fat) and in food composition: steak, baked potato, lettuce, carrots, salad dressing, cake, strawberries, bread, margarine, and coffee or tea. This was done to avoid potential influences of differing foodstuffs, albeit with similar nutrient composition, on post-prandial glucose and insulin responses [22-27]. The fibre content of the large meals was $0.02 \mathrm{~g} / \mathrm{kg}$ body weight and proportionately less for the smaller meals. Blood was sampled at $10-30$ min intervals from 07.30 to $23.00 \mathrm{~h}$ for plasma glucose 


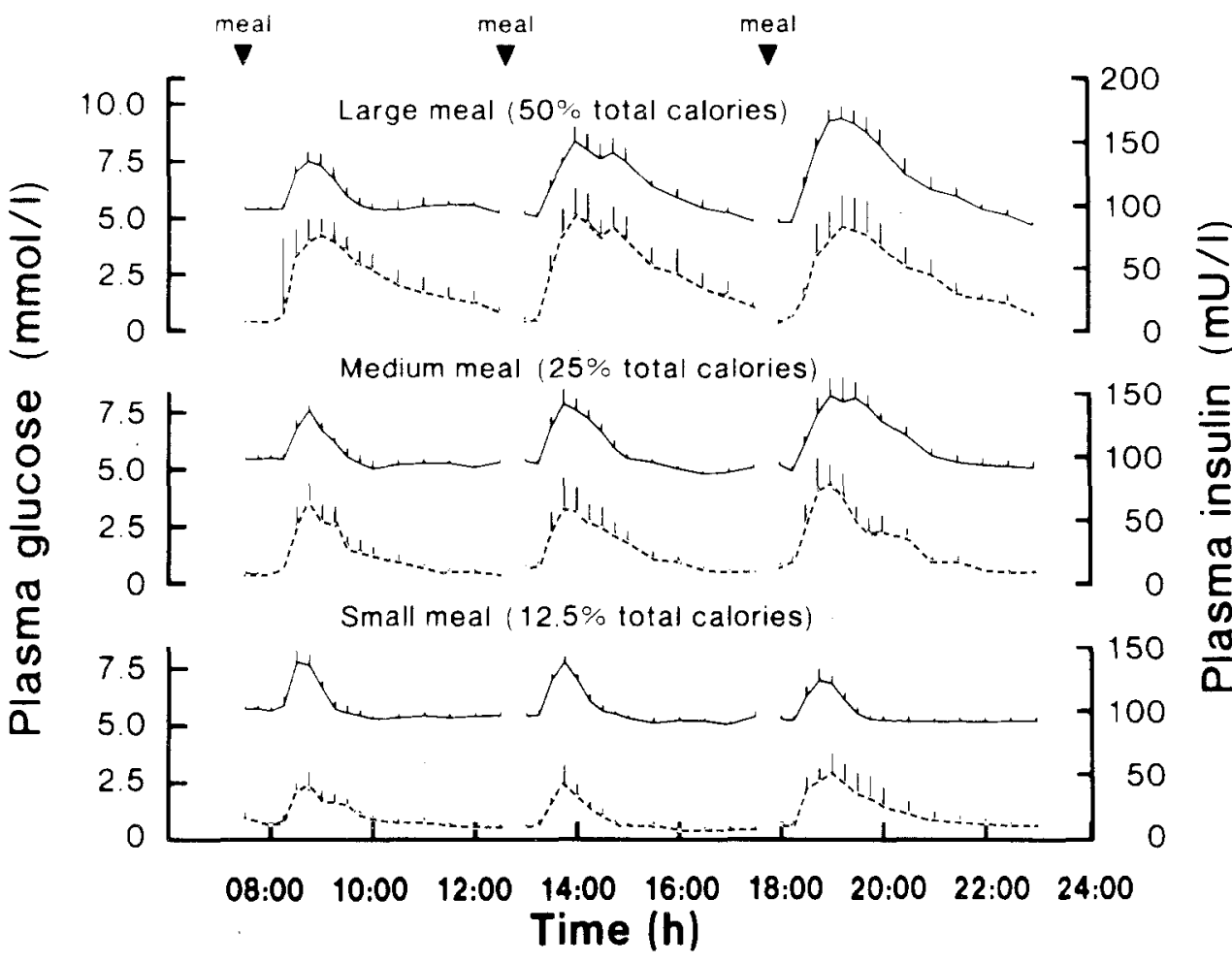

Fig. 1. Plasma glucose and insulin concentrations from six healthy subjects fed meals of-three different sizes on three different days in a randomized $3 \times 3$ Latin square design. The interruptions in data (mean \pm SEM) from meal to meal are due to the composite nature of the figures: meals of differing size, not the same size, were taken during a single day. Interrupted line $=$ plasma insulin; solid line $=$ plasma glucose

(Yellow Springs Instruments model $23 \mathrm{~A}$ glucose analyzer), insulin [28], C-peptide (Calbiochem, San Diego, California) [29], gastric inhibitory polypeptide (GIP) [30], and glucagon [31] analyses. Insulin secretion was calculated from the plasma C-peptide concentrations using a spline function assuming equimolar secretion of insulin and C-peptide and a 2-compartment model of distribution of C-peptide [32].

\section{Statistical Analysis}

Statistical analysis was performed by an analysis of variance, Spearman rank correlation coefficient, and Student's t-test. A $p$ value $<0.05$ was taken as significant.

\section{Results}

Effects of Meal Size on Plasma Glucose, Insulin, GIP, and Glucagon Concentrations (Figs. 1, 2)

Post-prandial plasma glucose, insulin, and GIP concentrations increased progressively as meal size increased from $12.5 \%$ to $50 \%$ of total calories. There were significant associations between meal size and post-prandial plasma glucose $(p<0.001)$, insulin $(p=0.02)$ and GIP $(p=0.003)$. This increase was evident whether assessed as peak post-prandial concentrations of plasma glucose $(7.6 \pm 0.2,8.3 \pm 0.3,8.8 \pm 0.4 \mathrm{mmol} / \mathrm{l})$, insulin $(48 \pm 7$, $70 \pm 11,95 \pm 12 \mathrm{mU} / 1)$ and GIP $(0.74 \pm 0.1,1.06 \pm 0.15$, $1.64 \pm 0.31 \mathrm{pmol} / \mathrm{l})$, or as integrated concentrations of plasma glucose $(94.4 \pm 5.6, \quad 205.6 \pm 66.7, \quad 366.7 \pm$ $\left.116.7 \mathrm{mmol} \cdot \mathrm{l}^{-1} \cdot 300 \mathrm{~min}^{-1}\right)$, insulin $(39 \pm 15,73 \pm 16$, $\left.176 \pm 26 \mathrm{mU} \cdot \mathrm{l}^{-1} \cdot 300 \mathrm{~min}^{-1}\right)$ and $\operatorname{GIP}(1.8 \pm 1.4,4.8 \pm 1.2$,
$19.8 \pm 3.0 \mathrm{nmol}^{-1} \cdot 300 \mathrm{~min}^{-1}$ ), for the small, medium, and large meals, respectively. There was no effect of meal size on post-prandial plasma glucagon concentrations.

Effect of Time of Meal Ingestion on Plasma Glucose, Insulin, GIP, and Glucagon Concentrations and Insulin Secretion (Figs. 1, 3, 4)

Post-prandial plasma glucose concentrations increased progressively from 08.00 to $18.00 \mathrm{~h}(p=0.006)$ for the medium and large meals. This increase was evident when assessed either as peak post-prandial plasma glucose concentrations $(7.8 \pm 0.2, \quad 8.3 \pm 0.6,8.8 \pm$ $0.7 \mathrm{mmol} / 1 \quad$ (medium); $7.8 \pm 0.4, \quad 8.7 \pm 0.6, \quad 9.9 \pm$ $0.6 \mathrm{mmol} / 1$ (large), or as integrated plasma glucose $\left[122.2 \pm 38.9, \quad 150.0 \pm 33.3, \quad 338.9 \pm 61.1 \mathrm{mmol} \cdot \mathrm{l}^{-1}\right.$. $300 \mathrm{~min}^{-1}$ (medium); 166.7 $\pm 38.9,361.1 \pm 77.8,577.8 \pm$ $88.9 \mathrm{mmol} \cdot 1^{-1} \cdot 300 \mathrm{~min}^{-1}$ (large)] at $08.00,13.00$ and $18.00 \mathrm{~h}$, respectively. Peak post-prandial plasma glucose concentrations exceeded $10 \mathrm{mmol} / \mathrm{l}$ in four subjects after ingestion of the large meal. There was no influence of time of day on plasma insulin, GIP or glucagon responses to the three meal sizes.

Since the greatest effects of time of day on plasma glucose concentrations were observed for the large meal, calculations of insulin secretion were limited to that meal. Despite increases of approximately $30 \%$ in plasma insulin $\left(165 \pm 49\right.$ versus $215 \pm 52 \mathrm{mU} \cdot \mathrm{l}^{-1}$. $\left.300 \mathrm{~min}^{-1}\right)$ and insulin secretion (5.6 \pm 1.0 versus $7.5 \pm$ 0.5 units) from 08.00 to $13.00 \mathrm{~h}$, there was a doubling of plasma glucose responses $(172.2 \pm 50.0$ versus $388.9 \pm$ 

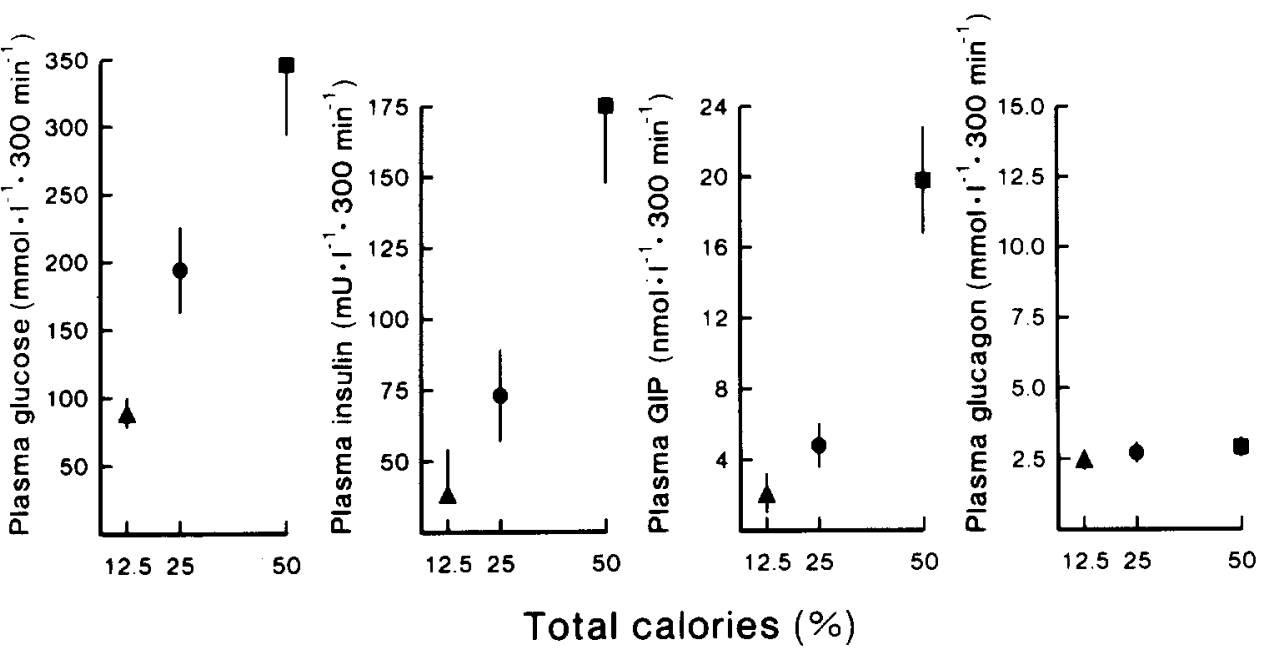

Fig. 2. Effect of meal size on plasma glucose, insulin, GIP, and glucagon responses expressed as mean $\pm \mathrm{SEM}$ for areas under the curves for meals of different size. $\Delta=$ small meal; = medium meal; $\mathbf{\square}=$ large meal

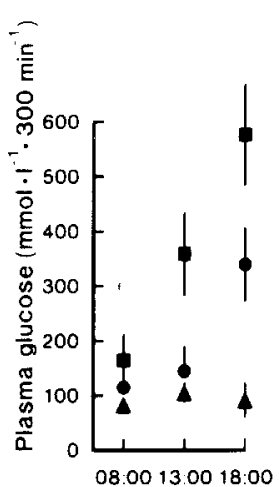

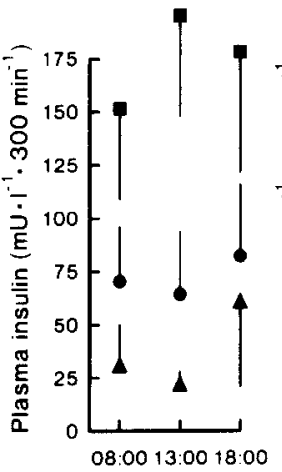

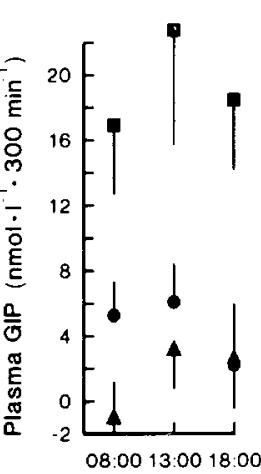

Time (h)
4

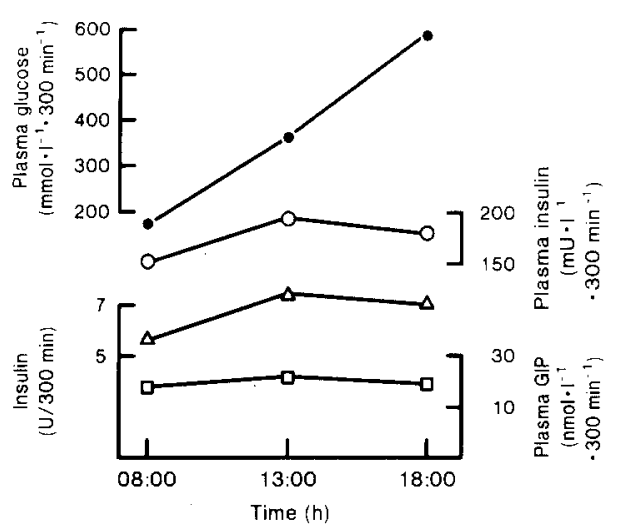

Fig.3. Effect of time of day of meal ingestion on plasma glucose, insulin, GIP, and glucagon responses expressed as mean \pm SEM of areas under the curves for meals of different size. $\boldsymbol{\Lambda}=$ small meal; $\mathbf{O}=$ medium meal; $\mathbf{\square}=$ large meal

Fig.4. Plasma glucose, insulin and GIP responses expressed as mean \pm SEM for areas under the curves, and insulin secretion estimated using a spline function applied to C-peptide measurements, for the large meal taken at $08.00,13.00$ and $18.00 \mathrm{~h}$

Table 1

\begin{tabular}{|c|c|c|c|c|c|c|}
\hline \multirow{4}{*}{ Time of meals } & \multicolumn{6}{|c|}{ Meal sequence } \\
\hline & \multicolumn{3}{|l|}{ I } & \multicolumn{3}{|l|}{ II } \\
\hline & \multicolumn{6}{|c|}{ Study day } \\
\hline & $\bar{A}$ & B & $\mathrm{C}$ & $\mathrm{A}$ & $B$ & $\mathrm{C}$ \\
\hline $08.00 \mathrm{~h}$ & $\mathrm{~L}$ & $S$ & $M$ & $\mathrm{~L}$ & $S$ & M \\
\hline $13.00 \mathrm{~h}$ & M & $\mathrm{L}$ & S & $\mathrm{S}$ & $\mathrm{M}$ & $\mathrm{L}$ \\
\hline $18.00 \mathrm{~h}$ & $S$ & $\mathrm{M}$ & $\mathrm{L}$ & $\mathrm{M}$ & $\mathrm{L}$ & $S$ \\
\hline
\end{tabular}

$\mathrm{L}=$ large meal ( $50 \%$ total daily calories); $\mathrm{M}=$ medium meal ( $25 \%$ total daily calories); $\mathrm{S}=$ small meal $(12.5 \%$ total daily calories)

$\left.83.3 \mathrm{mmol} \cdot 1^{-1} \cdot 300 \mathrm{~min}^{-1}\right)$. In the face of a further increase in plasma glucose concentrations from 13.00 to $18.00 \mathrm{~h} \quad\left(388.9 \pm 93.3\right.$ versus $594.4 \pm 111.1 \mathrm{mmol} \cdot \mathrm{l}^{-1}$. $300 \mathrm{~min}^{-1}$ ), there were no further changes in plasma insulin $\left(215 \pm 52\right.$ versus $\left.213 \pm 53 \mathrm{mU} \cdot \mathrm{l}^{-1} \cdot 300 \mathrm{~min}^{-1}\right)$ and insulin secretion $(7.5 \pm 0.5$ versus $7.0 \pm 0.9$ units $)$.

\section{Effect of Sequence of Meal Ingestion on Plasma Glucose, Insulin and GIP Concentrations}

There was no effect of sequence of meal ingestion as an independent variable or as a modulator of other variables such as meal size and/or time of day of meal ingestion on plasma glucose, insulin, GIP or glucagon responses.

\section{Discussion}

Under normal ambulatory conditions healthy individuals eat meals throughout the day that may vary widely in size. The current studies demonstrate that in normal subjects meal tolerance decreases as the day progresses due to a decrease in insulin action in the absence of a compensatory increase in insulin secretion. Ingestion of meals varying in caloric content from $12.5 \%$ to $50 \%$ of total calories was associated with proportionate increases in post-prandial plasma glucose, insulin and 
GIP concentrations. Sequence of meal ingestion was without effect on any of the above variables.

Most but not all previous studies have observed a progressive increase in plasma glucose concentrations with increasing glucose loads [1-7]. Although a significant association between meal size and post-prandial plasma glucose concentration was observed in the current studies when the data from all meals were assessed, the effect of meal size on meal tolerance was dependent on time of day. This relationship was most prominent when meals were ingested at $18.00 \mathrm{~h}$ but was not detectable at $08.00 \mathrm{~h}$. At $13.00 \mathrm{~h}$ the plasma glucose responses to the large meal exceeded those of the medium and small meals but the latter two did not differ. At $08.00 \mathrm{~h}$ there were no differences in plasma glucose responses among the three sizes of meals. These observations are consistent with those of Cohn et al. [8] who noted no differences in post-prandial plasma glucose responses to meals varying in size from 145 to 580 calories when ingested at $08.00 \mathrm{~h}$. The effects of varying size of meals at other times of the day were not examined by those investigators.

Post-prandial plasma glucose concentrations frequently exceeded $10 \mathrm{mmol} / 1$ after the large meal in the current studies, which contrasts with other studies in which healthy subjects fed meals consisting of $30 \%-35 \%$ of total daily calories as the evening meal had peak post-prandial plasma glucose concentrations of less than $8.3 \mathrm{mmol} / 1$ [33-35]. This observation suggests that currently proposed goals for peak post-prandial plasma glucose concentrations for diabetic subjects may be too stringent $[36,37]$.

The correlation between meal size and post-prandial plasma insulin concentrations reported previously [8] is consistent with the well established relationship between glucose load and plasma insulin responses [3, 5-7]. The post-prandial plasma insulin responses in this study were potentially mediated by both plasma glucose and GIP concentrations. The latter hormone (which is secreted from the small bowel in response to enteral administration of glucose, fat and selected amino acids) is often considered to be the primary mediator of the enteroinsular axis [38]. Associations between GIP release and the size of oral glucose and triglyceride loads have been reported in animals $[39,40]$. The current studies demonstrate a highly significant association between meal size and post-prandial plasma GIP responses. No such relationship was observed between meal size and post-prandial plasma glucagon responses.

The current studies indicate a progressive deterioration in carbohydrate tolerance to mixed meals throughout the day. It has long been recognized that there is a diurnal variation in response to oral glucose loads, characterized by reduced tolerance later in the day [9-14]. A similar effect has not been uniformly reported for carbohydrate tolerance to mixed meals [15-18]. Reduced carbohydrate tolerance to mixed meals was observed by Owens et al [18], and, although not comment- ed on by Genuth [16], is evident from analysis of his data; Ahmed et al observed the phenomenon in females and not males [17]. In contrast, Malherbe et al. reported that there was no evidence for a diurnal variation in carbohydrate tolerance to mixed meals [15]. However, in the latter study, although no change in carbohydrate tolerance during the day was reported when the data from all time periods were analyzed, when integrated responses were compared for each time period carbohydrate tolerance was worse late in the day than earlier. The failure to recognize a diurnal variation in carbohydrate tolerance to mixed meals in some previous studies may derive in part from the size of the test meal. In the present study the effect of time of day on meal tolerance was most evident with a meal which constituted a larger caloric challenge (50\% of total daily calories) than in previous studies ( $33 \%$ of total daily calories). Although this meal was approximately $1000 \mathrm{Kcal}$, its size and composition was similar to that eaten in a typical evening dinner.

The deterioration of carbohydrate tolerance to mixed meals during the day appears to result from both impaired insulin secretion and impaired insulin action. Impaired insulin secretion is demonstrated by the fact that, despite progressive increases in post-prandial plasma glucose concentrations during the day, there was no concomitant increase in insulin release as reflected by either plasma insulin concentrations or C-peptide secretion. These observations are consistent with previous reports of a progressive impairment of insulin responses to oral glucose loads during the day [10-14, 41]. Furthermore, insulin responses to intravenous glucose have been reported to be greater in the morning than in the evening [12, 42]. The similarity in diurnal responses of plasma insulin between intravenous and oral glucose challenges obviates the participation of the enteroinsular axis in this phenomenon. This conclusion is consistent with the lack of diurnal change in plasma GIP concentrations in the current study. Although a diurnal alteration in hepatic clearance of insulin could account for the lack of change in plasma insulin concentrations during the day, the absence of a diurnal effect on insulin secretion calculated by C-peptide concentrations makes this possibility unlikely.

Decreased insulin secretion alone does not appear to be sufficient to explain the progressive deterioration in carbohydrate tolerance to mixed meals during the day. The progressive increase in plasma glucose concentrations in the face of unchanging insulin secretion and plasma insulin concentrations suggests an impairment in insulin action. This speculation is consistent with the reports that intravenous insulin resulted in greater hypoglycaemia in the morning than later in the day $[12,41,43]$. Although the design of the current study does not permit an assessment of the mechanism for a diurnal impairment of insulin action, decreased insulin sensitivity could arise from decreased insulin receptor binding following meal ingestion later in the day [44]. It 
is not known whether this phenomenon is due to downregulation of insulin binding as a result of higher insulin levels during the day than during the night. Although plasma levels of growth hormone, cortisol and catecholamines were not measured in the current study, it is unlikely that the progressive decrease in insulin action can be attributed to excess secretion of these hormones since peak concentrations of these hormones usually occur in the morning [45-48].

Thus, in nondiabetic man meal tolerance is influenced both by size of meal and time of day of meal ingestion but not by sequence of meal ingestion. As meal size increases post-prandial glycaemia and insulin secretion increase proportionately. Meal tolerance decreases progressively throughout the day because of both a decrease in insulin action and a lack of any compensatory increase in insulin secretion.

Acknowledgements. The excellent technical assistance of J.King, T.Lund, J.Kaul, W. Blanchard, K. Kluge, J.Jay, M. Koch, S. Beilke, and the staff of the General Clinical Research Center is gratefully acknowledged. Supported in part by grants from the NIH (AM 8-2218, AM 20973, AM 20411, RR 00585) and Mayo Foundation.

\section{References}

1. West KM, Wulff JA, Reigel DG, Fitzgerald DT (1964) Oral carbohydrate tolerance tests. Arch Int Med 113: 641-648

2. Sisk CW, Burnham DE, Stewart J, McDonald GW (1970) Comparison of the 50 and 100 gram oral glucose tolerance test. Diabetes 19: 852-862

3. Castro A, Scott JP, Grettie D, Macforlane D, Baily RE (1970) Plasma insulin and glucose responses of healthy subjects to varying glucose loads during three-hour oral glucose tolerance tests. Diabetes 19: $842-852$

4. Toeller M, Knussmann R (1973) Reproducibility of oral glucose tolerance tests with three different loads. Diabetologia 9: 102-107

5. Bratusch-Marrain PR, Waldhausl WK, Gasic S, Korn A, Nowotny $P$ (1980) Oral glucose tolerance test: effect of different glucose loads on splanchnic carbohydrate and substrate metabolism in healthy Man. Metabolism 29:289-295

6. deNobel E, van't Laar A (1978) The size of the loading dose as an important determinant of the results of the oral glucose tolerance test. A study in subjects with slightly impaired glucose tolerance. Diabetes 27: $42-48$

7. Mosora F, Lacroix M, Luyckx A, Pallikarakis N, Pirnay F, Krzentowski G, Lefebvre P (1981) Glucose oxidation in relation to the size of the oral glucose loading dose. Metabolism 30: 1143-1149

8. Cohn C, Berger S, Norton M (1968) Relationship between meal size and frequency and plasma insulin response in man. Diabetes $17: 72-75$

9. Bowen AJ, Reeves RL (1967) Diurnal variation in glucose tolerance. Arch Int Med 119:261-264

10. Jarrett RJ, Keen H (1969) Diurnal variation of oral glucose tolerance: a possible pointer to the evolution of diabetes mellitus. $\mathrm{Br}$ Med J 2:341-344

11. Jarrett RJ, Keen H (1970) Further observations on the diurnal variation in oral glucose tolerance. Br Med J 4: 334-337

12. Carrol KF, Nestel PJ (1973) Diurnal variation in glucose tolerance and insulin secretion in man. Diabetes 22: 333-348

13. Zimmet PZ, Wall JR, Rome R, Stimmler L, Jarrett RJ (1974) Diurnal variation in glucose tolerance: associated changes in plasma insulin, growth hormone and non-esterified fatty acids. Br Med J 1: $485-491$
14. Aparicio NJ, Puchulu FE, Gagliardino JJ, Ruiz M, Llorens JM, Ruiz J, Lamas A, DeMiguel R (1974) Circadian variation of the blood glucose, plasma insulin and human growth hormone levels in response to an oral glucose load in normal subjects. Diabetes 23: $132-137$

15. Malherbe C, DeGasparo M, DeHertogh R, Hoet JJ (1969) Circadian variations of blood sugar and plasma insulin levels in man. Diabetologia 5: 397-404

16. Genuth SM (1973) Plasma insulin and glucose profiles in normal, obese and diabetic persons. Ann Int Med 79: 812-822

17. Ahmed M, Gannon MC, Nuttall FQ (1976) Post-prandial plasma glucose, insulin, glucagon and triglyceride responses to a standard diet in normal subjects. Diabetologia 12: 61-67

18. Owens DR, Wragg KC, Briggs PI, Luzio S, Kimber G, Davies C (1979) Comparison of the metabolic response to a glucose tolerance test and a standardized test meal and the response to serial test meals in normal healthy subjects. Diabetes Care 2: 409-413

19. Staub H (1921) Untersuchungen über den Zuckerstoffwechsel des Menschen. I. Mitteilung Z Klin Med 91: 44

20. Traugott K (1922) Über das Verhalten des Blutzuckerspiegels bei wiederholter und verschiedener Art enteraler Zuckerzufuhr und dessen Bedeutung für die Leberfunktion. Klin Wochenschr 1: 892

21. Yalow R, Goldsmith S, Berson S (1969) Influence of physiologic fluctuations in plasma growth hormone on glucose tolerance. Diabetes 18: 402-408

22. Crapo PA, Insel J, Sperling M, Kolterman O (1981) Comparison of serum glucose, insulin and glucagon responses to different types of complex carbohydrate in noninsulin-dependent diabetic patients. Am J Clin Nutr 34: 184-190

23. Hassinger W, Sauer G, Cordes U, Krause U, Beyer J, Baessler RH (1981) The effects of equal caloric amounts of xylitol, sucrose and starch on insulin requirements and blood glucose levels in insulin dependent diabetics. Diabetologia 21: 37-40

24. Crapo PA, Reaven G, Olefsky J (1977) Post-prandial plasma glucose and insulin responses to different complex carbohydrates. Diabetes 26: 1178-1183

25. Crapo PA, Reaven G, Olefsky J (1976) Plasma glucose and insulin responses to orally administered simple and complex carbohydrates. Diabetes 25: 741-747

26. Carlston A, Greenfield M, Kraemer FB, Tobey RA, Reaven GM (1980) Effect of source of dietary carbohydrate on plasma glucose and insulin responses to test meals in normal subjects. Am J Clin Nutr 33: 1279-1282

27. Thompson RG, Hayford JT, Danney MM (1978) Glucose and insulin responses to diet. Effect of variations in source and amount of carbohydrate. Diabetes 27: 1020-1026

28. Nagakawa S, Nakayama H, Sasaki T, Yochinok Yu YY, Shinozaki K, Akoi S, Moshimo K (1973) A simple method for the determination of serum free insulin levels in insulin-treated patients. Diabetes $22: 290-600$

29. Faber OK, Binder C, Markussen J, Heding LG, Naithani VK, Kuzuya H, Blix P, Horwitz DL, Rubenstein AH (1978) Characterization of seven C-peptide antisera. Diabetes 27 (Suppl 1): 170-177

30. Kuzio M, Dryburgh JR (1979) Gastric inhibitory polypeptide. In: Jaffe B, Behrman $\mathrm{H}$ (eds) Methods of hormone radioimmunoassay. 2nd ed. Academic Press, New York, pp 541-552

31. Faloona GR, Unger R (1974) Glucagon. In: Jaffe B, Behrman H (eds) Methods of hormone radioimmunoassay. 2nd ed. Academic Press, New York, pp 317-330

32. Eaton RP, Allen RC, Schade DS, Erickson KM, Standefer J (1980) Prehepatic insulin production in man: kinetic analysis using peripheral connecting peptide behavior. J Clin Endocrinol Metab 51: $520-528$

33. Service FJ (1978) Normalization of plasma glucose of unstable diabetes: studies under ambulatory fed conditions with pumped intravenous insulin. J Lab Clin Med 91: 480-489

34. Nelson RL, Service FJ, Go VLW (1980) Interrelationships among insulin, glucagon and gastric inhibitory polypeptide in insulinoma. Mayo Clin Proc 55: 138-145

35. Rizza RA, Gerich JE, Haymond MW, Westland RE, Hall LD, Clemens AH, Service FJ (1980) Control of blood sugar in insulin-de- 
pendent diabetes: comparison of an artificial endocrine pancreas, continuous subcutaneous insulin infusion and intensified conventional insulin therapy. N Engl J Med 303: 1313-1318

36. Skyler JS, Seigler DE, Reeves ML (1982) Optimizing pumped insulin delivery. Diabetes Care 5: 135-139

37. Nathan DM, Lou P, Avruch J (1982) Intensive conventional and insulin pump therapies in adult Type I diabetes. Ann Int Med 97: $31-36$

38. Creutzfeldt W (1979) The incretin concept today. Diabetologia 16: $75-85$

39. Schulz TB, Burhal PG, Jorde R, Waldum HL (1981) Gastric inhibitory polypeptide release into the portal vein in response to intraduodenal glucose loads in anesthetized rats. Scand J Gastroenterol 16: 1061-1065

40. Pederson RA, Schubert HE, Brown JC (1975) Gastric inhibitory polypeptide. Its physiologic release and insulinotropic action in the dog. Diabetes 24: 1050-1056

41. Sensi S, Capani F, Caradonna P, Policicchio D, Carotenuto M (1970) Diurnal variation of insulin response to glycemic stimulus. Biochem Biolog Sper 9: 153-156

42. Wichelow MJ, Sturge RA, Keen H, Jarrett RJ, Stimmler L, Grainger S (1974) Diurnal variation in response to intravenous glucose. Br Med J 1: 488-491
43. Gibson T, Jarrett RJ (1972) Diurnal variation in insulin sensitivity. Lancet 2: 947-948

44. Beck-Nielsen H, Pederson O (1978) Diurnal variation in insulin binding to human monocytes. J Clin Endocrinol Metab 47: 385-390

45. Follenius M, Brandenburger G, Hietter B, Semeoni M, Reinhardt B (1982) Diurnal cortisol peaks and their relationships to meals. J Clin Endocrinol Metab 55: 757-761

46. Saar N, Gordon R (1979) Variability in plasma catecholamine levels: age duration and time of day. Br J Clin Pharm 8: 353-358

47. Sauerbier I, Mayersbach H (1977) Circadian variation of catecholamines in human blood. Horm Metab Res 9:529-530

48. Rudman D, Kutner M, Rogers C, Lubin M, Fleming G, Bain R (1981) Impaired growth hormone secretion in the adult population: relation to age and adiposity. J Clin Invest 67:1361-1369

Received: 13 December 1982

and in revised form: 25 April 1983

Dr. F.J.Service

Mayo Clinic

Rochester, MN 55905, USA 